\title{
AKUMULASI DATA DARI DATABASE MULTISUMBER (STUDI KASUS: PENILAIAN ANGKA KREDIT DOSEN DI UPN "VETERAN" JAWA TIMUR)
}

\author{
Intan Yuniar Purbasari ${ }^{1)}$, Henni Endah Wahanani ${ }^{2)}$ \\ ${ }^{1,2)}$ Teknik Informatika, Fakultas Ilmu Komputer, UPN “Veteran” Jawa Timur \\ Jl. Raya Rungkut Madya, Gunung Anyar, Surabaya 60294 \\ E-Mail: intanyuniar.if@ upnjatim.ac.id ${ }^{1)}$; henniendah.if@upnjatim.ac.id ${ }^{2)}$
}

\begin{abstract}
ABSTRAK
Jabatan akademik dosen adalah sebuah karir dan juga merupakan pengakuan kemampuan seorang dosen dalam menjalankan Tridharma Perguruan Tinggi. Untuk dapat memperolehnya, setiap dosen harus menjalani serangkaian penilaian kredit poin (Penilaian Angka Kredit-PAK) sesuai dengan aturan yang telah ditetapkan oleh pemerintah melalui Direktoral Jenderal Pendidikan Tinggi, yang sekarang berada di bawah Kementerian Riset, Teknologi, dan Pendidikan Tinggi. Dosen yang dinilai harus mengisi sejumlah dokumen yang mendata kegiatan tridharma-nya selama setidaknya empat tahun ke belakang. Selain itu, setiap semester mereka juga diharuskan mengisi dokumen serupa dalam bentuk laporan Beban Kerja Dosen (BKD), berbasis Microsoft Access. Di sisi lain, UPN "Veteran" Jawa Timur juga telah mencatat data-data pribadi, pendidikan, dan sejarah akademis semua pegawainya dalam sistem informasi internal SIMPEG (Sistem Informasi Manajemen Pegawai, berbasis Borland Delphi) dan juga SIDOS (Sistem Informasi Dosen, berbasis Microsoft SQL Server) yang juga harus diisi dan rutin diupdate oleh tiap pegawai/dosen. Pada dasarnya data di ketiga sistem informasi tersebut adalah serupa dan dapat digunakan dalam proses PAK untuk menjaga konsistensi dan validitas data.

Penelitian ini bertujuan untuk mengumpulkan data dari sistem BKD dan SIMPEG dan mengintegrasikannya untuk membuat model aplikasi berbasis web untuk PAK. Terdapat total 76 data dosen dari 3 semester laporan BKD yang digunakan dalam penelitian ini. Tabel dari SIDOS digunakan sebagai template untuk desain tabel di database yang baru dibuat di sistem ini yang menggunakan framework Ruby on Rails.

Sebuah rintisan aplikasi web telah dibuat untuk menampilkan data yang telah dikumpulkan dan dapat dikustomisasi untuk menampilkan informasi yang berkaitan dengan kegiatan tridharma seorang dosen tertentu.
\end{abstract}

Kata Kunci : Penilaian Angka Kredit, BKD, database multisumber

\section{PENDAhuluan}

Jabatan akademik seorang dosen adalah sebuah karir dan pengakuan terhadap kemampuan dosen dalam menunaikan tugas tridharma perguruan tinggi dan sudah sepantasnya dosen selalu berusaha untuk meningkatkan karirnya hingga level yang tertinggi.

Pemerintah melalui Dirjen Dikti telah menetapkan pedoman operasional penilaian angka kredit kenaikan pangkat/jabatan akademik dosen terbaru tahun 2014 yang sudah sangat detil, komprehensif, dan terukur untuk setiap poin penilaiannya. Namun realitanya, beberapa dosen (terutama dosen yang baru pertama kali mengajukan usulan kenaikan jabatan akademik) masih kurang paham dengan cara pemberian nilai dan juga masih ada perbedaan persepsi di kalangan asesor penilai angka kredit yang dapat mengakibatkan perbedaan dalam pemberian nilai dan persyaratan lampiran yang harus dilengkapi oleh dosen yang mengajukan kenaikan jabatan.

Di lain pihak, lembaga, dalam hal ini UPN "Veteran" Jawa Timur telah sejak lama memiliki sistem informasi yang mencatat data-data pegawainya dan menyimpan data sejarah jabatan fungsional dan struktural tiap dosen serta data kegiatan tridharma per semester dalam Sistem Informasi Manajemen Kepegawaian (SIMPEG) dan Sistem Informasi Dosen (SIDOS) yang pengisiannya dilakukan oleh masing-masing dosen. Selain itu, sejak beberapa tahun terakhir semua dosen juga telah diwajibkan mengisi Laporan Beban Kinerja Dosen (BKD) tiap semester yang berisi daftar kegiatan tridharma dosen. Pada prinsipnya, data yang dimasukkan ke ketiga sistem ini adalah data yang sama dengan yang dibutuhkan untuk usulan kenaikan jabatan akademik dosen, sehingga akan lebih baik jika ketiga sistem tersebut dapat diintegrasikan untuk menjaga konsistensi dan validitas data sehingga semua pihak dapat memiliki persepsi yang sama. Selain itu, akan lebih baik jika terdapat fitur pendukung keputusan yang dapat membantu dosen pengusul untuk melakukan simulasi awal dari perhitungan nilai kredit yang dimiliki dan juga membantu asesor untuk mempercepat dan meningkatkan kualitas penilaian sehingga proses penilaian angka kredit dapat berjalan dengan lebih baik.

Tujuan dari penelitian ini adalah untuk membuat sebuah model rancangan aplikasi Sistem 
Pendukung Keputusan untuk penilaian kenaikan pangkat fungsional dosen yang datanya diambil dari sistem yang sudah dimiliki oleh lembaga. Tahap pertama ditargetkan untuk merancang model aplikasinya dan melakukan impor data dari existing system untuk mengisi kolom-kolom yang bersesuaian.

\section{TINJAUAN PUSTAKA}

Pemerintah melalui Peraturan Menteri Pendidikan dan Kebudayaan Republik Indonesia No. 92 Tahun 2014 telah mengeluarkan aturan tentang petunjuk teknis pelaksanaan penilaian angka kredit jabatan fungsional dosen [1]. Dosen yang telah memiliki NIDN mempunyai kedudukan sebagai tenaga profesional pada jenjang pendidikan tinggi. Kedudukan sebagai tenaga profesional tersebut dibuktikan dengan kepemilikan sertifikat pendidik yang diperoleh melalui uji kompetensi. Tunjangan profesi diberikan kepada dosen yang memiliki sertifikat pendidik, melaksanakan tridarma perguruan tinggi dengan beban kerja paling sedikit sepadan dengan 12 (dua belas) sks dan paling banyak 16 (enam belas) sks pada setiap semester, dan memenuhi persyaratan lainnya sesuai dengan peraturan perundang-undangan.

Sebagai bentuk akuntabilitas dosen, maka dosen diwajibkan melaporkan Beban Kerja Dosen setiap semester [2]. Kewenangan menjabarkan BKD diserahkan pada satuan pendidikan masingmasing (UU 14/2005 Pasal 73 ayat 3). Data rekapitulasi yang dilaporkan oleh satuan pendidikan tinggi dijadikan acuan pada penghitungan tunjangan profesi maupun tunjangan kehormatan bagi profesor. Disamping itu data ini dapat dijadikan acuan untuk pengembangan karir dosen selanjutnya (kenaikan jabatan akademik). Gambar 1 menunjukkan prosedur BKD di PTN, yang melibatkan dosen yang dinilai, asesor, dan institusi yang memberikan tunjangan profesi dan kehormatan kepada dosen.

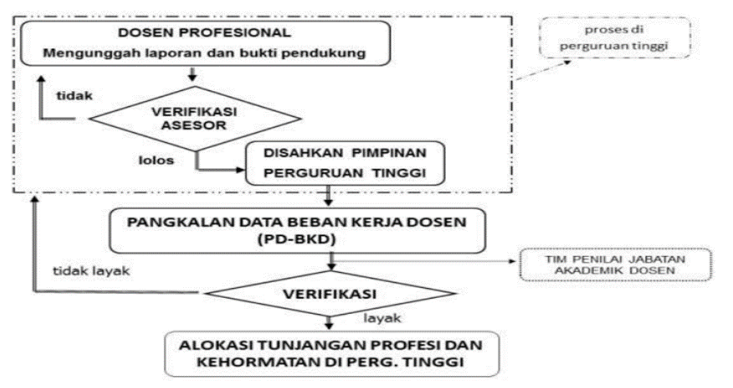

Gambar 1. Prosedur BKD di PTN

Gambar 2 menunjukkan format kompilasi laporan BKD yang dilakukan di tingkat fakultas dan universitas yang mendata seluruh kegiatan tridharma dosen di fakultas dan institusi tersebut. Institusi melalui Rektor kemudian melaporkan kepada Dirjen Dikti setiap tahunnya.

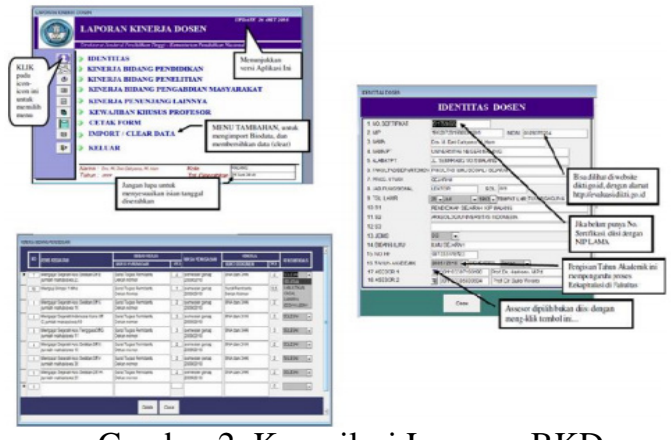

Gambar 2. Kompilasi Laporan BKD

\section{METODOLOGI}

Penelitian ini adalah penelitian eksploratif untuk mengembangkan sistem penilaian angka kredit untuk kenaikan jabatan akademik dosen yang terintegrasi dengan sistem yang sudah ada. Obyek penelitian adalah data dosen beserta histori kegiatan tridharma-nya selama tiga semester ke belakang.

Pada tahun pertama, penelitian ini difokuskan untuk pembuatan model dan rancangan awal sistem serta ujicoba akuisisi data dari sistem yang sudah ada. Proses pengambilan data dilakukan dengan menggunakan fasilitas impor pada tiap-tiap Database Management Systems (DBMS) yang digunakan oleh sistem yang ada. Setelah ujicoba, dilakukan peninjauan ulang terhadap data yang berhasil diimpor apakah telah sesuai dengan kriteria dan kategori yang tepat.

Pengembangan sistem bertujuan untuk merencanakan, merancang, dan membangun sistem yang lengkap dan jelas yang akan dimanfaatkan dalam implementasi aplikasi yang ditujukan untuk memenuhi kebutuhan pengguna sistem. Pengembangan sistem menggunakan daur Systems Development Life Cycle/SDLC [3] yang dimodifikasi untuk kepentingan penelitian:

1. Analisis sistem

Analisis sistem bertujuan untuk menentukan detail-detail yang terkait dengan sistem yang akan dikembangkan meliputi:

a) Identifikasi kebutuhan sistem

Sistem yang dibutuhkan adalah sebuah aplikasi sederhana (dapat berupa sebuah aplikasi berbasis web) agar dapat dijalankan dengan mudah tanpa perlu instalasi. Pada tahun pertama ini akan dibangun sebuah prototype aplikasi berbasis web untuk menampilkan data dosen dan kegiatan tridharma-nya.

b) Analisis kebutuhan data

Data diambil dari tiga sumber, yakni SIMPEG (data riwayat hidup, riwayat pendidikan, riwayat jabatan struktural dan fungsional), SIDOS (riwayat kegiatan mengajar tiap semester), dan BKD (riwayat kegiatan mengajar, penelitian, pengabdian kepada masyarakat, dan penunjang).

2. Akuisisi Data

Tahap ini adalah kegiatan untuk perolehan data dari ketiga sumber data. Karena ketiga sumber 
menggunakan database yang berbeda, maka tahap ini merupakan proses yang sangat kritis yang dapat menentukan kelanjutan proses penelitian.

3. Perancangan Antarmuka

Sebuah antarmuka sederhana akan dirancang untuk menampilkan hasil data yang berhasil diakuisisi.

4. Impor Data

Tahap berikutnya adalah mengambil data yang berhasil diakuisisi dan ditampilkan dalam aplikasi menggunakan antarmuka yang telah dirancang sebelumnya.

5. Ujicoba Hasil

Ujicoba hasil dilakukan menggunakan pendekatan testing Whitebox Testing [4] yang menguji sebuah software dengan melihat pada kode sumbernya langsung. Jika ditemukan kesalahan, maka baris kode yang menimbulkan kesalahan langsung dapat diperbaiki. Beberapa variasi pada Whitebox Testing juga akan dilakukan seperti yang dijelaskan oleh [5].

\section{Evaluasi}

Tujuan dari kegiatan evaluasi ini adalah untuk mendapatkan informasi dari hasil ujicoba yang telah dilakukan dan melakukan perbaikan (revisi) sistem agar menjadi lebih baik dan sesuai dengan tujuan pengembangan sistem.

7. Pembuatan Laporan

\section{HASIL DAN PEMBAHASAN}

Agar pengguna dapat dengan mudah mengakses sistem, maka aplikasi sistem dirancang agar berbasis web, yang akan meringankan sisi pengguna sehingga tidak perlu melakukan instalasi aplikasi. Peneliti memutuskan untuk menggunakan framework Ruby on Rails (RoR) yang menggunakan bahasa pemrograman Ruby, karena RoR merupakan salah satu framework pembuatan web yang modern dan berbasis open source. RoR juga telah menggunakan konsep MVC (Model View - Controller) yang merupakan model arsitektur pembuatan web yang memisahkan antara database (Model), tampilan halaman web (View), dan Controller yang mengatur akses ke Model dan menampilkan output pada View. RoR merupakan framework yang populer digunakan pada sejumlah website terkemuka seperti GitHub, Airbnb, SoundCloud, Hulu, dan banyak lagi.

Pada awal penelitian, data direncanakan akan diambil dari tiga sumber, yakni SIMPEG (data riwayat hidup, riwayat pendidikan, riwayat jabatan struktural dan fungsional), SIDOS (riwayat kegiatan mengajar tiap semester), dan BKD (riwayat kegiatan mengajar, penelitian, pengabdian kepada masyarakat, dan penunjang). Setelah dilakukan pengambilan data, diketahui bahwa data tridharma tiap dosen tersedia lebih lengkap pada BKD format MS Access dibandingkan pada SIDOS. Dengan pertimbangan tersebut, akhirnya diputuskan bahwa data tridharma yang diambil adalah dari BKD. Sedangkan dari SIDOS hanya diambil struktur tabelnya saja untuk dijadikan sebagai acuan dalam desain sistem yang akan dibuat. Database BKD yang diambil dan diujicoba adalah versi rekapitulasi yang direkap oleh Prodi Teknik Informatika pada semester genap TA 2015/2016. Tabel 1 menampilkan keterangan data yang diambil dari SIMPEG dan BKD:

Tabel 1. Data SIMPEG dan BKD

\begin{tabular}{|l|l|l|}
\hline Ket & \multicolumn{1}{|c|}{ SIMPEG } & \multicolumn{1}{c|}{ BKD } \\
\hline $\begin{array}{l}\text { Nama } \\
\text { file }\end{array}$ & $\begin{array}{l}\text { data_person } \\
\text { alia_2016.X } \\
\text { LS }\end{array}$ & $\begin{array}{l}\text { (1) LAPORAN_BKD_IF_GE } \\
\text { NAP_TA_2015_2016.mde } \\
\text { (2) LAPORAN_BKD_FTI_GE } \\
\text { NAP_TA_2015_2016.mde }\end{array}$ \\
\hline Ukuran & $3353 \mathrm{~KB}$ & $\begin{array}{l}1.2788 \mathrm{~KB} \\
2.3116 \mathrm{~KB}\end{array}$ \\
\hline $\begin{array}{l}\text { Jumlah } \\
\text { data }\end{array}$ & $\begin{array}{l}\text { 767 record } \\
\text { pegawai }\end{array}$ & $\begin{array}{l}1.13 \text { record dosen } \\
2.76 \text { record dosen }\end{array}$ \\
\hline
\end{tabular}

Database SIMPEG di server Telematika menggunakan DataBase Management System (DBMS) MS SQL Server versi 7. Saat akuisisi data, dilakukan ekspor database ke format MS Office Excel, yang menghasilkan 19 worksheets yang mewakili tiap tabelnya. Database BKD merupakan file executable dari DBMS MS Access (berekstensi .mde), yang merupakan bentuk aplikasi jadi dengan antarmuka yang berbasiskan database MS Access. Untuk dapat diakses tabel-tabelnya, file perlu berekstensi .accdb (ekstensi untuk file database Access versi 2007-2013). Sehingga perlu dilakukan ekspor data antar DBMS MS Access dan menghasilkan file REKAP_BKD.accdb dengan 20 tabel. Database dari sistem merupakan gabungan dari beberapa tabel-tabel yang diambil dari SIMPEG dan BKD, yang diambil sesuai dengan kebutuhan tabel yang diperlukan dalam Pengajuan Kepangkatan Dosen. Rincian desain tabel dapat dilihat pada tabel 2.

Sistem dibangun dengan menggunakan Ruby on Rails yang dibangun dalam lingkungan cloud (www.c9.io) dimana kode program dan interpreter Ruby sudah tertanam di dalamnya, sehingga tidak diperlukan instalasi Ruby on Rails di mesin lokal. Dalam tahap pembuatan awal aplikasi, telah dibuat rancangan model databasenya, yang menyesuaikan tabel dan kolom-kolom seperti pada desain tabel pada tabel 2. Rancangan database yang dibuat dari dalam Ruby on Rails masih dalam bentuk kosongan (menggunakan DBMS SQLite versi 3) yang akan diisi dengan data hasil akuisisi. Langkah-langkah yang dilakukan adalah sebagai berikut:

(1) Mengunduh database kosongan dari cloud ke komputer lokal dengan nama development.sqlite3

(2) Di komputer lokal menginstal dan menjalankan aplikasi DB Browser for SQLite. Aplikasi ini berguna untuk menampilkan database SQLite yang telah diunduh dan juga untuk memanipulasi database dengan menambahkan data/record maupun menambahkan tabel baru. 
Tabel 2. Desain Tabel Sistem

\begin{tabular}{|c|c|c|}
\hline Tabel & Kolom & Keterangan \\
\hline \multirow[t]{22}{*}{ MMDOS0 } & NOSERTI & $\begin{array}{l}\text { Dari REKAP_BKD, } \\
\text { tabel MMDOS0 }\end{array}$ \\
\hline & NIPDOS & $\begin{array}{c}\text { Dari REKAP_BKD, } \\
\text { tabel MMDOS0 }\end{array}$ \\
\hline & NIDNN & $\begin{array}{l}\text { Dari REKAP_BKD, } \\
\text { tabel MMDOS0 }\end{array}$ \\
\hline & NMDOS & $\begin{array}{l}\text { Dari REKAP_BKD, } \\
\text { tabel MMDOS0 }\end{array}$ \\
\hline & NMPT & $\begin{array}{c}\text { Dari REKAP_BKD, } \\
\text { tabel MMDOS0 }\end{array}$ \\
\hline & ALMPT & $\begin{array}{l}\text { Dari REKAP_BKD, } \\
\text { tabel MMDOS0 }\end{array}$ \\
\hline & FAKDOS & $\begin{array}{c}\text { Dari REKAP_BKD, } \\
\text { tabel MMDOS0 }\end{array}$ \\
\hline & PRODIDOS & $\begin{array}{c}\text { Dari REKAP_BKD, } \\
\text { tabel MMDOS0 }\end{array}$ \\
\hline & PANGKAT & $\begin{array}{c}\text { Dari REKAP_BKD, } \\
\text { tabel MMDOS0 }\end{array}$ \\
\hline & GOL & $\begin{array}{c}\text { Dari REKAP_BKD, } \\
\text { tabel MMDOS0 }\end{array}$ \\
\hline & TGLHR & $\begin{array}{c}\text { Dari REKAP_BKD, } \\
\text { tabel MMDOS0 }\end{array}$ \\
\hline & TPLHR & $\begin{array}{l}\text { Dari REKAP_BKD, } \\
\text { tabel MMDOS0 }\end{array}$ \\
\hline & PTS1 & $\begin{array}{c}\text { Dari REKAP_BKD, } \\
\text { tabel MMDOS0 }\end{array}$ \\
\hline & PTS2 & $\begin{array}{c}\text { Dari REKAP_BKD, } \\
\text { tabel MMDOS0 }\end{array}$ \\
\hline & PTS3 & $\begin{array}{c}\text { Dari REKAP_BKD, } \\
\text { tabel MMDOS0 }\end{array}$ \\
\hline & KATDOS & $\begin{array}{c}\text { Dari REKAP_BKD, } \\
\text { tabel MMDOS0 }\end{array}$ \\
\hline & BIDILDOS & $\begin{array}{c}\text { Dari REKAP_BKD, } \\
\text { tabel MMDOS0 }\end{array}$ \\
\hline & NOHP & $\begin{array}{c}\text { Dari REKAP_BKD, } \\
\text { tabel MMDOS0 }\end{array}$ \\
\hline & KDPT & $\begin{array}{c}\text { Dari REKAP_BKD, } \\
\text { tabel MMDOS0 }\end{array}$ \\
\hline & KDKOP & $\begin{array}{c}\text { Dari REKAP_BKD, } \\
\text { tabel MMDOS0 }\end{array}$ \\
\hline & NMKOP & $\begin{array}{c}\text { Dari REKAP_BKD, } \\
\text { tabel MMDOS0 }\end{array}$ \\
\hline & THN_PROP & $\begin{array}{c}\text { Dari REKAP_BKD, } \\
\text { tabel MMDOS0 }\end{array}$ \\
\hline \multirow[t]{9}{*}{ TDIK } & Nip & $\begin{array}{c}\text { Dari SIMPEG, tabel } \\
\text { riwayatpendidikan }\end{array}$ \\
\hline & Namapendidikan & $\begin{array}{c}\text { Dari SIMPEG, tabel } \\
\text { riwayatpendidikan }\end{array}$ \\
\hline & Thlulus & $\begin{array}{l}\text { Dari SIMPEG, tabel } \\
\text { riwayatpendidikan }\end{array}$ \\
\hline & Keterangan & $\begin{array}{c}\text { Dari SIMPEG, tabel } \\
\text { riwayatpendidikan }\end{array}$ \\
\hline & Tg1_lulus & $\begin{array}{c}\text { Dari SIMPEG, tabel } \\
\text { riwayatpendidikan }\end{array}$ \\
\hline & AngkaKredit & Data PAK \\
\hline & JmlAngkaKredit & Data PAK \\
\hline & BuktiFisik & Data PAK \\
\hline & KodeBuktiFisik & Data PAK \\
\hline \multirow[t]{7}{*}{ TJAR } & Nip & Dari SIMPEG \\
\hline & NOPEND & $\begin{array}{c}\text { Dari REKAP_BKD, } \\
\text { tabel TRAJAR0 }\end{array}$ \\
\hline & NMPEND & $\begin{array}{c}\text { Dari REKAP_BKD, } \\
\text { tabel TRAJAR0 }\end{array}$ \\
\hline & BUKTIPEND & $\begin{array}{c}\text { Dari REKAP_BKD, } \\
\text { tabel TRAJAR0 }\end{array}$ \\
\hline & SKSPEND & $\begin{array}{c}\text { Dari REKAP_BKD, } \\
\text { tabel TRAJAR0 }\end{array}$ \\
\hline & MASAPEND & $\begin{array}{c}\text { Dari REKAP_BKD, } \\
\text { tabel TRAJAR0 }\end{array}$ \\
\hline & DOKPEND & $\begin{array}{c}\text { Dari REKAP_BKD, } \\
\text { tabel TRAJAR0 }\end{array}$ \\
\hline
\end{tabular}

Tabel 2. Desain Tabel Sistem (Lanjutan)

\begin{tabular}{|c|c|c|}
\hline Tabel & Kolom & Keterangan \\
\hline & SKSPEND2 & $\begin{array}{c}\text { Dari REKAP_BKD, } \\
\text { tabel TRAJAR0 }\end{array}$ \\
\hline & REKPEND & $\begin{array}{c}\text { Dari REKAP_BKD, } \\
\text { tabel TRAJAR0 }\end{array}$ \\
\hline & SatuanHasil & Data PAK \\
\hline & JumlahVolKeg & $\begin{array}{c}\text { Data PAK, }= \\
\text { SKSPEND } \\
\text { REKAP_BKD tabel } \\
\text { TRAJAR0 }\end{array}$ \\
\hline \multirow[t]{15}{*}{ TLIT } & Nip & Dari SIMPEG \\
\hline & NOPEN & $\begin{array}{c}\text { Dari REKAP_BKD, } \\
\text { Tabel TRPEN0 }\end{array}$ \\
\hline & NMPEN & $\begin{array}{c}\text { Dari REKAP_BKD, } \\
\text { Tabel TRPEN0 }\end{array}$ \\
\hline & BUKTIPEN & $\begin{array}{c}\text { Dari REKAP_BKD, } \\
\text { Tabel TRPEN0 }\end{array}$ \\
\hline & SKSPEN & $\begin{array}{c}\text { Dari REKAP_BKD, } \\
\text { Tabel TRPEN0 }\end{array}$ \\
\hline & MASAPEN & $\begin{array}{c}\text { Dari REKAP_BKD, } \\
\text { Tabel TRPEN0 }\end{array}$ \\
\hline & DOKPEN & $\begin{array}{c}\text { Dari REKAP_BKD, } \\
\text { Tabel TRPEN0 }\end{array}$ \\
\hline & SKSPEN2 & $\begin{array}{c}\text { Dari REKAP_BKD, } \\
\text { Tabel TRPEN0 }\end{array}$ \\
\hline & REKPEN & $\begin{array}{c}\text { Dari REKAP_BKD, } \\
\text { Tabel TRPEN0 }\end{array}$ \\
\hline & SatuanHasil & Data PAK \\
\hline & JumlahVolKeg & $\begin{array}{c}\text { Data PAK, = SKSPEN } \\
\text { REKAP_BKD tabel } \\
\text { TRPEN0 }\end{array}$ \\
\hline & AngkaKredit & Data PAK \\
\hline & JmlAngkaKredit & Data PAK \\
\hline & BuktiFisik & $\begin{array}{c}\text { Data PAK, }= \\
\text { BUKTIPEN } \\
\text { REKAP_BKD tabel } \\
\text { TRPEN0 } \\
\end{array}$ \\
\hline & KodeBuktiFisik & Data PAK \\
\hline \multirow[t]{15}{*}{ TABDI } & Nip & Dari SIMPEG \\
\hline & NOPBM & $\begin{array}{c}\text { Dari REKAP_BKD, } \\
\text { Tabel TRPBM0 }\end{array}$ \\
\hline & NMPBM & $\begin{array}{c}\text { Dari REKAP_BKD, } \\
\text { Tabel TRPBM0 }\end{array}$ \\
\hline & BUKTIPBM & $\begin{array}{c}\text { Dari REKAP_BKD, } \\
\text { Tabel TRPBM0 }\end{array}$ \\
\hline & SKSPBM & $\begin{array}{c}\text { Dari REKAP_BKD, } \\
\text { Tabel TRPBM0 }\end{array}$ \\
\hline & MASAPBM & $\begin{array}{c}\text { Dari REKAP_BKD, } \\
\text { Tabel TRPBM0 }\end{array}$ \\
\hline & DOKPBM & $\begin{array}{c}\text { Dari REKAP_BKD, } \\
\text { Tabel TRPBM0 }\end{array}$ \\
\hline & SKSPBM2 & $\begin{array}{c}\text { Dari REKAP_BKD, } \\
\text { Tabel TRPBM0 }\end{array}$ \\
\hline & REKPBM & $\begin{array}{c}\text { Dari REKAP_BKD, } \\
\text { Tabel TRPBM0 }\end{array}$ \\
\hline & SatuanHasil & Data PAK \\
\hline & JumlahVolKeg & $\begin{array}{c}\text { Data PAK, = SKSPBM } \\
\text { REKAP_BKD tabel } \\
\text { TRPBM0 }\end{array}$ \\
\hline & AngkaKredit & Data PAK \\
\hline & JmlAngkaKredit & Data PAK \\
\hline & BuktiFisik & $\begin{array}{c}\text { Data PAK, }= \\
\text { BUKTIPBM } \\
\text { REKAP_BKD tabel } \\
\text { TRPBM0 }\end{array}$ \\
\hline & KodeBuktiFisik & Data PAK \\
\hline
\end{tabular}


Tabel 2. Desain Tabel Sistem (Lanjutan)

\begin{tabular}{|c|c|c|}
\hline Tabel & Kolom & Keterangan \\
\hline \multirow{15}{*}{ TLAIN } & Nip & Dari SIMPEG \\
\hline & NOLAIN & $\begin{array}{c}\text { Dari REKAP_BKD, } \\
\text { Tabel TRLAIN0 } \\
\end{array}$ \\
\hline & NMLAIN & $\begin{array}{c}\text { Dari REKAP_BKD, } \\
\text { Tabel TRLAIN0 }\end{array}$ \\
\hline & BUKTILAIN & $\begin{array}{c}\text { Dari REKAP_BKD, } \\
\text { Tabel TRLAIN0 }\end{array}$ \\
\hline & SKSLAIN & $\begin{array}{c}\text { Dari REKAP_BKD, } \\
\text { Tabel TRLAIN0 }\end{array}$ \\
\hline & MASALAIN & $\begin{array}{c}\text { Dari REKAP_BKD, } \\
\text { Tabel TRLAIN0 }\end{array}$ \\
\hline & DOKLAIN & $\begin{array}{c}\text { Dari REKAP_BKD, } \\
\text { Tabel TRLAIN0 }\end{array}$ \\
\hline & SKSLAIN2 & $\begin{array}{c}\text { Dari REKAP_BKD, } \\
\text { Tabel TRLAIN0 } \\
\end{array}$ \\
\hline & REKLAIN & $\begin{array}{c}\text { Dari REKAP_BKD, } \\
\text { Tabel TRLAIN0 } \\
\end{array}$ \\
\hline & SatuanHasil & Data PAK \\
\hline & JumlahVolKeg & $\begin{array}{c}\text { Data PAK, = } \\
\text { SKSLAIN } \\
\text { REKAP_BKD tabel } \\
\text { TRLAIN0 }\end{array}$ \\
\hline & AngkaKredit & Data PAK \\
\hline & JmlAngkaKredit & Data PAK \\
\hline & BuktiFisik & $\begin{array}{c}\text { Data PAK, = } \\
\text { BUKTILAIN } \\
\text { REKAP_BKD tabel } \\
\text { TRLAIN0 }\end{array}$ \\
\hline & KodeBuktiFisik & Data PAK \\
\hline \multirow[t]{6}{*}{ TFUNG } & Nip & $\begin{array}{l}\text { Dari SIMPEG, tabel } \\
\text { riwayatfabatanfungsi }\end{array}$ \\
\hline & Pangkat & $\begin{array}{l}\text { Dari SIMPEG, tabel } \\
\text { riwayatfabatanfungsi }\end{array}$ \\
\hline & Nokep & $\begin{array}{l}\text { Dari SIMPEG, tabel } \\
\text { riwayatfabatanfungsi }\end{array}$ \\
\hline & Pejabat & $\begin{array}{l}\text { Dari SIMPEG, tabel } \\
\text { riwayatfabatanfungsi }\end{array}$ \\
\hline & TMT & $\begin{array}{l}\text { Dari SIMPEG, tabel } \\
\text { riwayatfabatanfungsi }\end{array}$ \\
\hline & Tgl & $\begin{array}{l}\text { Dari SIMPEG, tabel } \\
\text { riwayatfabatanfungsi }\end{array}$ \\
\hline
\end{tabular}

(3) Mengkonversi tabel-tabel yang bersesuaian di database data_personalia_2016.xls (yakni tabel riwayatpendidikan dan riwayatjabatanfungsi) ke format file teks dan dari database REKAP_BKD.accdb mengambil tabel-tabel seperti yang dijelaskan pada tabel 1 .

(4) Melakukan impor data melalui menu yang telah disediakan oleh DB Browser for SQLite untuk semua tabel yang telah dikonversi ke format file teks ke database development.sqlite3.

(5) Melakukan unggah (upload) ulang file database development.sqlite3 yang telah diisi data ke lingkungan cloud.

\section{A. Ujicoba Hasil}

Setelah database diunggah, maka ditulis beberapa file controller untuk mengatur pengambilan data dari database dan menampilkan ke aplikasi. Gambar 3 menunjukkan contoh sebuah file controller mmdos0_controller.rb yang mengatur pengambilan data dari tabel mmdos0.

Untuk keperluan antar muka, juga telah ditulis beberapa file html untuk menampilkan data yang telah diambil dari database. Tampilan awal aplikasi seperti pada gambar 4.

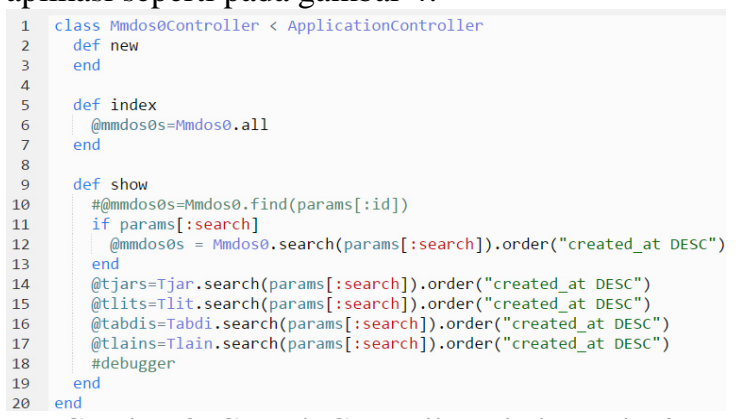

Gambar 3. Contoh Controller tabel Mmdos0

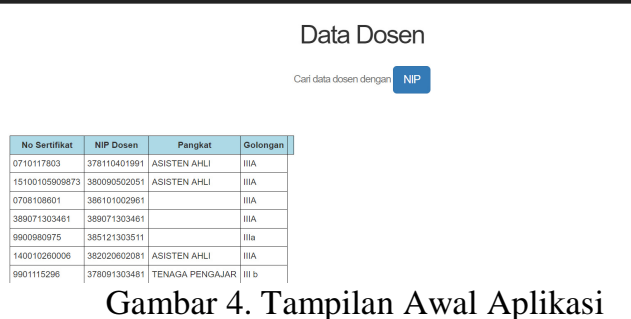

Gambar 4 menunjukkan tampilan halaman awal aplikasi dimana seluruh data yang tersimpan dalam database akan ditampilkan. Di bagian atas terdapat fitur untuk mencari data dosen berdasarkan NIP atau No Sertifikat, jika dosen yang akan dicari telah memiliki sertifikat dosen. Jika tombol diklik, maka tampilan akan berpindah ke halaman yang lain untuk view data (yang membuka file HTML show.html.erb). Di halaman tersebut, jika pengguna memasukkan sebuah nomor NIP atau Nomor Sertifikasi Dosen, maka akan ditampilkan data untuk dosen yang sesuai seperti pada gambar 5 .

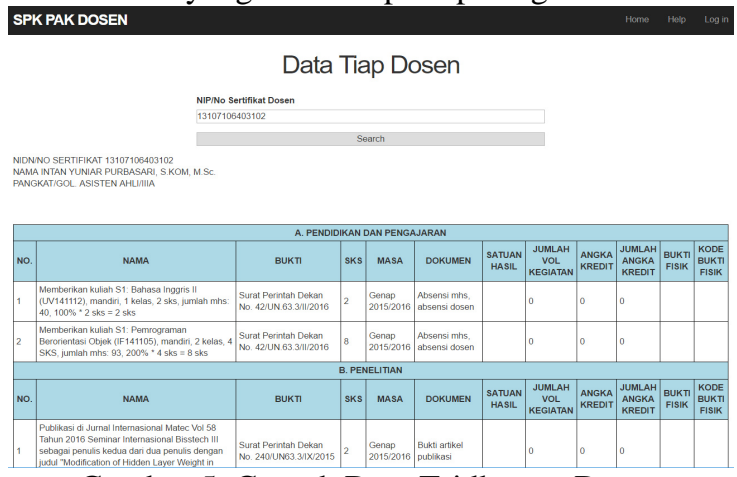

Gambar 5. Contoh Data Tridharma Dosen

\section{B. Pembahasan}

Proses koleksi dan konversi data dari SIMPEG dan BKD merupakan tahapan yang paling penting yang membutuhkan waktu dan ketelitian ekstra untuk memetakan dari format data lama ke format data baru. Sebagai contoh, dari aplikasi BKD dapat ditarik tabel mmdos0 yang memiliki 22 kolom seperti pada tabel 3. Tabel ini digunakan untuk mencatat informasi biodata yang berkaitan dengan dosen. 
Tabel 3. Perbedaan antara kolom tabel mmdos0 di aplikasi BKD dengan desain sistem

\begin{tabular}{|c|c|c|c|}
\hline \multicolumn{2}{|c|}{ Aplikasi BKD } & \multicolumn{2}{|r|}{ Desain Sistem } \\
\hline No. & Kolom & No. & Kolom \\
\hline 1. & NOSERTI & 1. & ID \\
\hline 2. & NIPDOS & 2. & NOSERTI \\
\hline 3. & NIDNN & 3. & NIPDOS \\
\hline 4. & NMDOS & 4. & NIDNN \\
\hline 5. & NMPT & 5. & NMDOS \\
\hline 6. & ALMPT & 6. & NMPT \\
\hline 7. & FAKDOS & 7. & ALMPT \\
\hline 8. & PRODIDOS & 8. & FAKDOS \\
\hline 9. & PANGKAT & 9. & PRODIDOS \\
\hline 10. & GOL & 10. & PANGKAT \\
\hline 11. & TGLHR & 11. & GOL \\
\hline 12. & TPLHR & 12. & TGLHR \\
\hline 13. & PTS1 & 13. & TPLHR \\
\hline 14. & PTS2 & 14. & PTS1 \\
\hline 15. & PTS3 & 15. & PTS2 \\
\hline 16. & KATDOS & 16. & PTS3 \\
\hline 17. & BIDILDOS & 17. & KATDOS \\
\hline 18. & NOHP & 18. & BIDILDOS \\
\hline 19. & KDPT & 19. & NOHP \\
\hline 20. & KDKOP & 20. & KDPT \\
\hline 21. & NMKOP & 21. & KDKOP \\
\hline 22. & THN_PROP & 22. & NMKOP \\
\hline & & 23. & THN_PROP \\
\hline & & 24. & CREATED_AT \\
\hline & & 25. & UPDATED_AT \\
\hline
\end{tabular}

Pada tabel mmdos0 yang digunakan dalam sistem, ditambahkan 3 kolom baru, yakni id, created_at, dan updated_at. Kolom id digunakan untuk memberikan nomor tiap baris data, sedangkan kolom created_at dan updated_at merupakan kolom yang dihasilkan secara otomatis oleh Rails ketika tabel dibuat dan digunakan untuk mencatat jam dan tanggal ketika suatu baris data dibuat dan di-update.

Pada Tabel 4 ditunjukkan contoh perbedaan tabel tjar yang ditarik dari BKD yang memiliki 11 kolom dengan tabel yang dibuat dalam system yang memiliki 19 kolom. Tabel ini digunakan untuk menyimpan data pengajaran dosen.

Di tabel tjar versi sistem, selain ditambahkan kolom ID, juga 6 kolom baru (satuan_hasil, jml_vol_keg, angka_kredit, jml_angka_kredit, bukti_fisik, dan kode_bukti_fisik) yang mengacu pada kolom isian di form penilaian angka kredit dosen dalam surat pernyataan kegiatan mengajar. Di tabel tridharma yang lain (tlit, tabdi, dan tlain) juga telah ditambahkan kolom yang sama untuk menyimpan data angka kredit dari tiap kegiatan yang dilakukan. Ini untuk mempersiapkan pengembangan aplikasi ke arah Sistem Pendukung Keputusan yang dapat melakukan simulasi perhitungan angka kredit dosen yang direncanakan akan dilakukan pada penelitian berikutnya.
Tabel 4. Perbedaan antara kolom tabel tjar di aplikasi BKD dengan desain sistem

\begin{tabular}{|c|l|c|l|}
\hline \multicolumn{2}{|c|}{ Aplikasi BKD } & \multicolumn{2}{c|}{ Desain Sistem } \\
\hline No. & \multicolumn{1}{|c|}{ Kolom } & No. & \multicolumn{1}{|c|}{ Kolom } \\
\hline 1. & SMTPT & 1. & ID \\
\hline 2. & KDPT & 2. & SMTPT \\
\hline 3. & NOSERTI & 3. & NOSERTI \\
\hline 4. & NOPEND & 4. & NOPEND \\
\hline 5. & NMPEND & 5. & NMPEND \\
\hline 6. & BUKTIPEND & 6. & BUKTIPEND \\
\hline 7. & SKSPEND & 7. & SKSPEND \\
\hline 8. & MASAPEND & 8. & MASAPEND \\
\hline 9. & DOKPEND & 9. & DOKPEND \\
\hline 10. & SKSPEND2 & 10. & SKSPEND2 \\
\hline 11. & REKPEND & 11. & REKPEND \\
\hline & & 12. & satuan_hasil \\
\hline & & 13. & Jml_vol_keg \\
\hline & & 14. & Angka_kredit \\
\hline & & 15. & Jml_angka_kredit \\
\hline & & 16. & Bukti_fisik \\
\hline & & 17. & Kode_buktiffisik \\
\hline & & 18. & CREATED_AT \\
\hline & & 19. & UPDATED_AT \\
\hline
\end{tabular}

Dari hasil yang didapat dan telah dibahas di atas, dapat dikatakan bahwa penelitian ini telah dapat menghasilkan model rancangan aplikasi yang menjadi embrio untuk pembuatan Sistem Pendukung Keputusan untuk penilaian kenaikan pangkat fungsional dosen. Data yang dibutuhkan telah dapat diambil dari sistem yang sudah dimiliki oleh lembaga, sehingga input ulang data dapat diminimalisir, bahkan ditiadakan, sehingga konsistensi data dapat terjaga. Selain itu, karena laporan BKD per semester memiliki lebih sedikit data untuk tiap dosennya dibandingkan dengan isian pada format Penilaian Angka Kredit Dosen, maka asesor BKD akan lebih ringan dalam melakukan tugas validasi tiap kegiatan dan diharapkan dapat lebih cepat untuk meluluskan laporan BKD dosen yang dinilai. Jika laporan BKD seorang dosen telah dinilai lulus, maka kevalidan data pada laporan yang akan dibaca ke dalam Sistem Pendukung Keputusan juga akan terjaga.

\section{KESIMPULAN}

Dari ujicoba dan pembahasan yang telah dilakukan, maka dapat diambil beberapa kesimpulan yang berkaitan dengan penelitian sebagai berikut:

1. Sebuah model database telah dihasilkan sebagai tahap awal untuk pembuatan Sistem Pendukung Keputusan Penilaian Angka Kredit Dosen. Model database ini memiliki 11 tabel yang menyimpan data kegiatan tridharma beserta tabel penunjang lain yang dibutuhkan.

2. Data-data yang dibutuhkan dalam pembuatan SPK telah dapat diambil dari sistem yang telah dimiliki oleh lembaga, yakni SIMPEG dan BKD dengan menggunakan SIDOS sebagai kerangka pembuatan tabel-tabel yang dibutuhkan. 
3. Sebanyak 76 data sampel dosen yang diambil dari rekapitulasi laporan BKD Fakultas Teknologi Industri telah dimasukkan ke dalam database sistem untuk laporan 3 semester ke belakang, yakni Semester Genap 2015/2016, Semester Gasal 2015/2016, dan Semester Genap 2014/2015.

4. Sebuah aplikasi web sederhana telah dibuat untuk menampilkan data kegiatan tridharma dosen yang telah dimasukkan ke dalam sistem yang dibangun dengan framework Ruby on Rails dengan penyimpanan berbasis cloud. Aplikasi ini merupakan rintisan dari aplikasi SPK yang akan dibuat dan sementara ini telah dapat menampilkan data kegiatan tiap dosen berdasarkan input NIP atau Nomor Sertifikat Pendidik dari dosen.

\section{Acknowledgement}

Penulis mengucapkan terima kasih yang sebesar-besarnya kepada UPN "Veteran" Jawa Timur yang telah mendanai penelitian ini dalam skema Riset Dasar (RISDA) Lembaga Penelitian dan Pengabdian kepada Masyarakat (LPPM) tahun 2016.

\section{DAFTAR PUSTAKA}

[1]. Dirjen DIKTI, 2014. Pedoman Operasional Penilaian Angka Kredit Kenaikan Pangkat/Jabatan Akademik Dosen. Kementerian Pendidikan dan Kebudayaan.

[2]. Dirjen DIKTI, 2015. Pedoman BKD: Workshop Pengisian. Kementerian Riset Teknologi dan Pendidikan Tinggi.

[3]. Wilkinson, J. W., Michael J. Cerullo, Vasant Raval, Bernard Wong-on-Wing. 2000. Accounting Information Systems, $4^{\text {th }}$ Edition, John Willey and Sons, Inc., New York.

[4]. Williams, Laurie. 2006. "White-Box Testing" (PDF): 60-61, 69. Diambil 18 Februari 2016

[5]. Ehmer Khan, Mohd, 2011, "Different Approaches to White Box Testing Technique for Finding Errors" $(P D F)$. International Journal of Software Engineering and Its Applications 5: 1-6. Diambil 18 Februari 2016 